\title{
La fotografía en el aula de ciencias: propuestas didácticas
}

\author{
Jesús Martínez Pérez y Berenice Martínez Cuatepotzo
}

\section{Resumen}

En este trabajo se proponen dos estrategias para la enseñanza de la química a nivel medio superior, en donde se utilizan como herramientas principales el teléfono inteligente (smartphone) y la fotografía. Las propuestas presentadas son integrales, porque además de lograr los aprendizajes estipulados en los programas de estudios, permiten que el estudiante se relacione con su entorno, desarrolle habilidades de expresión escrita e de intercambio ideas.

Palabras clave: Fotografía, educación, química, teléfono inteligente.

\section{Photography IN the SCIENCE CLASSROOM: DIDACTIC PROPOSALS}

\begin{abstract}
This work is proposing two teaching strategies for high school Chemistry students, using photography and a smartphone as the main tool. These are integrating strategies, because besides achieving the learning of curricular contents, they allow students to positively relate to their environment and develop writing and idea-sharing skills.
\end{abstract}

Keywords: Photography, education, Chemistry, smartphone.

Recepción: 27/05/2020. Aprobación: 18/01/2021. Dol: http://doi.org/10.22201/cuaieed.16076079e.2021.22.2.8 


\section{Berenice Martínez Cuatepotzo}

berenice.martinez@cch.unam.mx orcid.org/0000-0001-9277-0309

Química Farmacéutica Bióloga y maestra en Ciencias Bioquímicas por parte de la unam en la Facultad de Química. Estudió una carrera técnica en bibliotecología. Tiene experiencia laboral como responsable sanitario y auxiliar de la jefa de asuntos regulatorios en Grupo Farmacos. Es profesora del Colegio de Ciencias y Humanidades plantel Sur desde 2014. En 2019 ganó el primer lugar en el concurso universitario de imágenes fijas "Espacios de aprendizaje y enseñanza de la comunidad UNAM" en la categoría imagen fija "De los espacios donde mejor enseño", organizado por la codeic.

Jesús Martínez Pérez

jemape@gmail.com orcid.org/0000-0001-8743-75362

Químico Farmacéutico Biólogo de formación, Maestro en Docencia para la Educación media superior. Ambos por la Facultad de Química de la unam. Certificado por Laureate Universities en 2015 en enseñanza en "Educación Online, híbrida y Blended". Con 8 años de experiencia como docente de nivel medio superior en las áreas de Ciencias Naturales y Experimentales. Dos años de experiencia en la participación de elaboración de reactivos para la evaluación docente en CENEVAL. Línea de investigación en el área experimental Educativa. 


\section{Introducción}

En 2020, la mayoría de los estudiantes de nivel medio superior en zonas urbanas de la República mexicana cuentan con acceso a una computadora o a un dispositivo móvil con internet (un smartphone) y son capaces de dominar sus funciones básicas, entre ellas el poder tomar, editar y distribuir fotografías a través de la red (Mendoza, 2014).

El uso de los teléfonos en el aula es un tema controversial, hay quienes sostienen que estos dispositivos dispersan la atención del estudiante y antagoniza su aprendizaje y como contraparte están los que consideramos que es una herramienta útil para potencializar el aprendizaje, si se usa apropiadamente para la búsqueda y el procesamiento de información, así como para generar y reproducir contenido multimedia.

Por otro lado, al tratarse principalmente de adolescentes, estos estudiantes encuentran en la fotografía una alternativa para expresar emociones de diversa índole, que pueden ser aprovechadas para explotar las experiencias de aprendizaje y ser vinculadas con la ciencia de una manera amigable, además la fotografía es apropiada con sus intereses y sus contextos. Se debe tomar en cuenta que para estos alumnos, que oscilan entre los 15 y 19 años, una parte importante de su rutina consiste en compartir y comentar experiencias en redes sociales por ello están en constante contacto con formatos y plataformas digitales como podcasts, blogger, Instagram, Facebook y Twitter (UNESCO, 2013).

Como el uso de los teléfonos inteligentes está arraigado entre estos estudiantes, es conveniente, que tanto ellos como los docentes, cuenten con un repertorio de propuestas didácticas cuidadosamente elaboradas para apoyar el cumplimiento de los objetivos de enseñanza y aprendizaje de todas las asignaturas (Riba, 2005).

En este trabajo describiremos dos propuestas didácticas que involucran el uso de la fotografía y el teléfono celular inteligente para trabajar el contenido curricular del programa de estudios de Química I del Colegio de Ciencias y Humanidades.

\section{Bases de la propuesta}

Las imágenes son representaciones icónicas que pueden conservar aquello experimentado en diferentes acontecimientos, estas representaciones, a su vez, son complementadas por representaciones inactivas y simbólicas en los procesos de aprendizaje (Camargo, 2010).

Aunque los medios audiovisuales imponen gran parte de los estilos de vida del mundo, las imágenes pueden generar una construcción icónica de la realidad y a su vez, ser susceptible a la percepción y a la interpretación de cada sujeto. 
La necesidad de orientar la diversidad de interpretaciones hace que sea necesario fundamentar las consideraciones, según la teoría de la Gestalt (Gómez, 2010). Para usar una imagen con propósitos educativos se requiere destacar las partes que la conforman, así como sus componentes y sus relaciones entre ellos, resaltando los elementos principales y poniendo énfasis a los conceptos claves (Praga-Lozano, 2018).

Cuando se presenta una imagen con las señalizaciones o anotaciones pertinentes explicando cuidadosamente lo que se quiere mostrar, el estudiante puede formular un modelo mental, según lo estudiado por Johnson-Laird (1980). Estos modelos incluyen conocimientos previos y expectativas y son por lo tanto, representaciones dinámicas de lo que se está estudiando. De lo anterior, surge la proposición de que la comprensión simbólica de un fenómeno natural se puede complementar con un modelo mental para mejorar el entendimiento de las leyes naturales.

En general, la teoría cognitiva del aprendizaje multimedia indica que se aprende mejor de una información si es presentada con palabras e imágenes más que con únicamente palabras, es decir, es necesario utilizar varios canales para reconfirmar la información. Las palabras e imágenes no son equivalentes, ni redundantes, ni sustituibles, sino complementarias; las imágenes se modifican con palabras que denotan su sentido, pues permite que el mensaje sea más claro, si la convergencia entre estos componentes es la apropiada (Raviolo, 2019).

Además de lo anterior, es conveniente destacar que la generación de fotografías e imágenes con intención de enseñanza y de aprendizaje en las ciencias, crea emociones positivas en el alumno, lo que provoca que recuerde el mensaje con mayor intensidad, lo interioriza como algo significativo.

Por lo tanto, el uso de la fotografía como aprendizaje debería emplearse en contextos digitales con el fin de apoyar a los estudiantes a relacionar conceptos con la vida cotidiana, generar abstracciones y reforzar su aprendizaje.

\section{Propuesta didáctica. Desafío fotográfico}

\section{Contexto}

La propuesta fue implementada en los "Cursos Intensivos" impartidos por el Colegio de Ciencias y Humanidades en el mes de mayo del 2019, en donde se tienen entre 25 a 30 estudiantes a cargo de un docente, cuya responsabilidad es propiciar el aprendizaje contemplado en los programas de estudio (en un total de 40 horas distribuidas en 10 sesiones). En estas circunstancias, resulta visiblemente complicado establecer actividades que logren el involucramiento total de los jóvenes estudiantes, pues su atención es fácil de perder y difícil de mantener. Es importante mencionar que muchos de los alumnos, dentro de estos cursos, no se encuentran vinculados con la ciencia, pues la mayoría son 
estudiantes de semestres terminales cuya atención está dirigida a iniciar sus estudios superiores en áreas ajenas a las ciencias naturales. Por lo cual, muchos ven a la química como algo que no tiene relación con sus intereses, ni con sus objetivos personales y mucho menos con su vida cotidiana. Para esta situación, resulta conveniente trabajar con lo que llamamos "desafíos fotográficos" del cual, su desarrollo se describe a continuación.

\section{Trabajo previo a cargo del docente}

Es importante mencionar que la propuesta puede usarse en cualquier asignatura y en cualquier campo de estudio. El docente tiene la labor de revisar los objetivos curriculares e identificar los aprendizajes que desea alcanzar, así como planearlos y dosificarlos, realizar un encuadre o lista de cotejo para delimitar las características que resulten más convenientes; también es su labor revisar que los estudiantes, organizados en equipos de no más de cuatro personas, planeen, presenten y comenten las fotografías que van a capturar. En este caso, se trabajó con un aprendizaje de química.

\section{Presentación de la actividad en el aula}

La actividad fue planteada de la siguiente manera en la sesión 1 del curso:

El profesor asignó un conjunto de planteamientos y en equipos de cuatro integrantes máximo, los estudiantes tomaron una fotografía que representara dichos planteamientosy los explicaron con una breve descripción, además fueron responsables de incorporarlas en una presentación de Power Point con sus anotaciones.

Cada equipo presentó sus fotografías y explicó por qué describen la petición planteada; la presentación fue organizada y comprensible para todos.

Se expuso lo siguiente como ejemplo:

Si el planteamiento del profesor es: Una mezcla homogénea líquida de color rojo, la siguiente diapositiva cumple correctamente con el planteamiento:

Imagen 1. Ejemplo de indicaciones dadas a los alumnos para resolver un reto fotográfico.

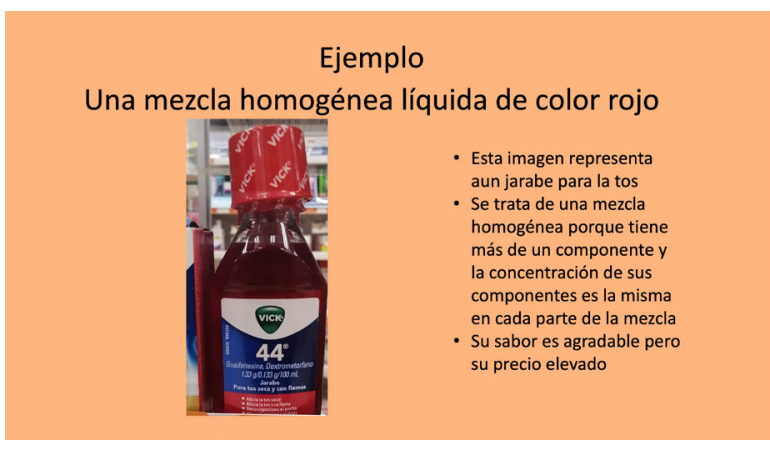

En seguida el profesor mostró algunos de sus planteamientos destinados a cumplir los objetivos del programa de estudios: 


\begin{tabular}{|l|l|}
\hline \multicolumn{1}{|c|}{ Planteamiento } & \multicolumn{1}{|c|}{ Aprendizaje esperado estipulado en el programa de estudios } \\
\hline $\begin{array}{l}\text { Una mezcla } \\
\text { homogénea líquida } \\
\text { de color }\end{array}$ & $\begin{array}{l}\text { Explica las diferencias entre mezcla y compuesto a nivel macroscópico, } \\
\text { con énfasis en sus propiedades características mediante la búsqueda } \\
\text { de información y el análisis de semejanzas y diferencias entre las } \\
\text { definiciones. (N2) } \\
\text { Reconoce la abundancia de las mezclas en el entorno cotidiano al } \\
\text { observar diferentes materiales y la presencia del agua en gran cantidad } \\
\text { de las mezclas. (N1) } \\
\text { Identifica usos del agua en la vida cotidiana y en la naturaleza, al } \\
\text { reflexionar acerca de su importancia. (N1) } \\
\text { Clasifica a las mezclas en heterogéneas y homogéneas e incluye dentro } \\
\text { de estas últimas a las disoluciones. (N1) }\end{array}$ \\
\hline $\begin{array}{l}\text { Una mezcla } \\
\text { heterogénea de dos líquidos que se usen } \\
\text { en la cocina }\end{array}$ & $\begin{array}{l}\text { Explica las diferencias entre mezcla y compuesto a nivel macroscópico, } \\
\text { con énfasis en las propiedades características, mediante la búsqueda } \\
\text { de información y el análisis de semejanzas y diferencias entre las } \\
\text { definiciones. (N2) } \\
\text { Reconoce la abundancia de mezclas en el entorno cotidiano al observar } \\
\text { los diferentes materiales y la presencia del agua en gran cantidad de las } \\
\text { mezclas. (N1) } \\
\text { Identifica usos del agua en la vida cotidiana y en la naturaleza, al } \\
\text { reflexionar acerca de su importancia. (N1) } \\
\text { Clasifica a las mezclas en heterogéneas y homogéneas e incluye dentro } \\
\text { de estas últimas a las disoluciones. (N1) }\end{array}$ \\
\hline
\end{tabular}

En seguida se presentan ejemplos de los resultados propuestos por los estudiantes.

Fotografía 1. Una mezcla homogénea líquida color rojo

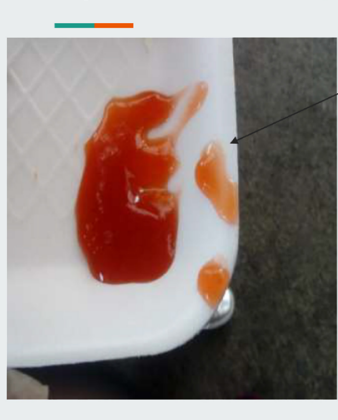

Descripción: es un poco de catsup en un plato de unicel de la catsup cafetería del cch sur.

Explicación:

esta es una mezcla homogénea líquida de color rojo ya que todas las sustancias y colorantes dan este que no se nota otro color mas que es plato blanco Dato curioso

En 1835 la catsup era considerado un medicamento contra la diarrea o cualquier problema digestivo
Imagen 2 (izquierda). Ejemplo de alumno para resolver un reto fotográfico.

Imagen $\mathbf{3}$ (derecha). Ejemplo de alumno para resolver un reto

fotográfico
Fotografía 9: la mezcla heterogénea de dos líquidos que se use en la cocina

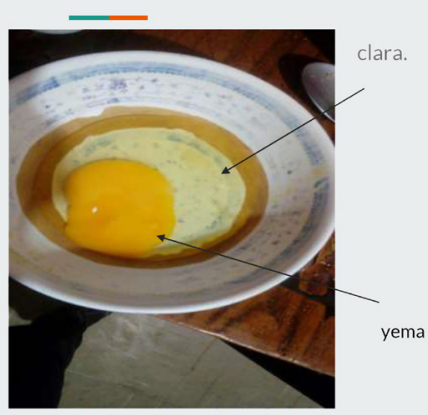

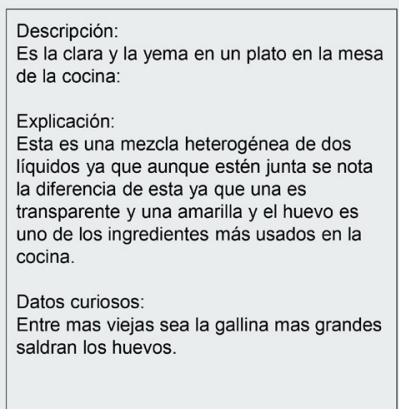

Descripción

Datos curiosos:

saldran los huevos.

El docente tiene la labor de recalcar en las instrucciones la importancia del texto, pues existe un principio de contigüidad espacial que sostiene que la explicación de la figura debe ser clara y concreta, sin generar una sobrecarga de información para evitar material extraño que sea excesivo en la imagen y palabras irrelevantes que desvíen la atención del usuario.

\section{Presentación y discusión del trabajo de los estudiantes}

Con el apoyo del material de proyección multimedia, los estudiantes mostraron sus fotografías en plenaria y al final de su presentación fueron retroalimentados 
por sus compañeros y por el docente. Esta experiencia resultó agradable porque el contenido que cada equipo presentó es diferente entre sí, además fueron comunes las aportaciones graciosas e inesperadas por parte de los estudiantes, que se convirtieron en objeto de controversia y debate.

Debido a que la instrucción de la actividad no requiere de una dificultad técnica que desanime al estudiante a realizarla, pues consiste en tomar una fotografía, discutirla y exponerla; y porque su presentación permite mostrar sus intereses, emociones y ocurrencias, la participación de los estudiantes es casi total. En los 2 grupos (48 alumnos) con los que se probó la propuesta, más del $83 \%$ de los alumnos lograron encontrar todas las mezclas que resolvían el reto.

Si bien, no existe un comparativo estricto con un grupo de control debido a la forma en la que se imparten estos cursos, es importante notar que la significación que los alumnos le dieron a los conceptos proviene de la relación que se hizo con su entorno.

\section{Segunda propuesta: "Ciencia en una foto"}

Como segunda propuesta, la fotografía puede ser utilizada como una herramienta para que los alumnos interioricen los aprendizajes por medio de la emotividad, comunicando a otros sobre la ciencia y aplicándola a los problemas sociales que los rodean. Funge como un factor emotivo para generar interés en el estudio de la química, de tal manera que se logra una mejor apertura emocional para después indagar otros contenidos de mayor dificultad.

La propuesta a la que llamamos "Ciencia en una foto", fue realizada en un curso regular de alumnos de primer semestre en agosto del 2019, con de tres grupos de 25 personas en promedio, y debido a que se encuentran dentro de las primeras semanas del bachillerato, no sólo son necesarias estrategias para conocerse y relacionarse entre ellos, sino también actividades que rompen el estereotipo de la ciencia.

\section{El rol del profesor en la propuesta}

El profesor solicitó a los alumnos producir una fotografía donde se observan cualquiera de los siguientes casos: a) los estados del agua en una sola imagen; b) contaminación del agua en su comunidad o c) usos del agua poco comunes que se dan en su comunidad; así como el envío de esta fotografía al correo electrónico del docente.

Las fotografías debían de ser inéditas, de propia autoría, a color o blanco y negro, con una descripción de máximo 300 caracteres que explicara con detalle un dato relevante de la imagen.

El profesor reunió las imágenes y las integró en una lotería. Las cartas de lotería fueron jugadas en clase, con lo cual se pueden cubrir los siguientes aprendizajes del programa de estudios: a) identificar usos del agua en la vida cotidiana y en la naturaleza al reflexionar acerca de su importancia; b) observa 
el agua en sus tres estados de agregación y los cambios entre estos al modificar la temperatura, con orden y responsabilidad, para comprender la naturaleza corpuscular de la materia.

Al finalizar el juego y después de ser observados, los alumnos por propia convicción comenzaron a interrogarse sobre ellas para abrir un debate sobre lo que pasa en sus comunidades. Hubo quienes comenzaron a presumir cuál es su imagen y cómo fue tomada y quienes expresaron sorpresa por no conocer un lugar que está dentro de su ciudad.

El profesor, con habilidad, deberá comprender que esas dudas son una gran oportunidad para crear en los alumnos la necesidad de aprender ciencia, y de verla como una herramienta para resolver problemáticas sociales, o generar hipótesis sobre de ellas, rompiendo los estereotipos y concepciones de la ciencia construidas por los medios de comunicación, que suelen plantearla como una actividad complicada, exclusiva y en ciertos casos hasta inalcanzable (Praga-Lozano, 2018). Para explicar la imagen los alumnos deberán destacar sus partes, sus componentes, las relaciones entre ellas y resaltar las ideas centrales, ya que se requiere que la imagen fotográfica sea realmente un documento sociocientífico y no solo decorativo.

El 95\% de los alumnos realmente logró tener una imagen que resaltara las temáticas de manera contundente así que el aprendizaje fue significativo pues las vivencias que evocan las imágenes van cargadas de sentimientos que les hacen reconsiderar a la ciencia como una forma de explicar el mundo, por lo cual el docente debe ser empático y valorar cada una de ellas, dando recomendaciones o retroalimentación de manera personal y teniendo especial cuidado de no emitir comentarios que descalifiquen las aportaciones.

Las fotografías revelan que sólo entre un 5\% y 10\% de los alumnos desconocen cómo obtener fotografías de buena calidad, cometiendo errores encuadre y composición; sin embargo, son ellos mismos quienes son críticos de su trabajo y logran aportar sugerencias a otros compañeros, por ello la actividad es también una buena oportunidad para conocerse y plantear acuerdos sobre la convivencia en la aula.

\section{Conclusión}

La fotografía digital es una herramienta muy valiosa que puede ser utilizada para la enseñanza de la química y la ciencia en general. Su uso, además de propiciar la tendencia del empleo y aprovechamiento de Tecnologías de la Información y Comunicación, permite que los estudiantes construyan conocimientos, logren aprendizajes significativos y compartan sus emociones y sus perspectivas personales con sus compañeros en una atmósfera de inclusión, respeto y tolerancia. Su uso, como parte de las actividades que pueden llevarse dentro y fuera del aula, permite que el alumno reflexione, discuta y debata sobre cuestiones sociocientíficas, para así permitir 
la formación de ciudadanos conscientes que puedan analizar críticamente problemas, dar hipótesis, soluciones y relacionar su cotidianidad con los conocimientos científicos y tecnológicos adquiridos en las aulas (Praga-Lozano, 2018).

\section{Referencias}

* Camargo,U.A.yHederich-Martínez,C.(2010).JeromeBruner:Dosteorías cognitivas, dos formas de significar, dos enfoques para la enseñanza de la ciencia. Psicogente, 13 (24), 329-346. https://www.redalyc.org/articulo.oa?id=497552357008

* Gómez Gómez, H. (2010) El adjetivo visual. De la figura retórica al significado de la imagen fotográfica. Revista de la SEECI, 22, Julio. Año XIII, 30-79. https://doi. org/10.15198/seeci.2010.22.30-79

Johnson-Laird, P. N. (1980). Mental Models in Cognitive Science. Cognitive Science, 4, 71-115. https://bit.ly/3riiLmf

Levie, W. y Lentz, R. (1982) The effects of text illustrations: A review of research. Educational Communication and Technology Journal, 30, 195-232

* Mendoza Bernal, M.I. (2014). El teléfono celular como mediador en el proceso de enseñanza-aprendizaje. Omnia, 20 (3), septiembre-diciembre, 9-22. https://www. redalyc.org/pdf/737/73737091002.pdf

* Parga-Lozano, D.L. y Piñeros-Carranza, G.Y. (2018) Enseñanza de la Química desde contenidos contextualizados. Educación Química, 29 (1), 55-64. http://dx.doi. org/10.22201/fq.18708404e.2018.1.63683

* Raviolo, A. (2019). Imágenes y enseñanza de la Química. Aportes de la Teoría cognitiva del aprendizaje multimedia. Educación Química, 30 (2), 114-128. http:// dx.doi.org/10.22201/fq.18708404e.2019.2.67174

* Riba Torrecillas, D., Soler-González J. y Rodríguez-Rosicha, A. (2005). ¿Puede ser una buena herramienta docente el uso de la cámara digital en un centro de atención primaria? Revista Atención Primaria, 35 (2), 105-107. https://doi. org/10.1157/13071918

* Organización de las Naciones Unidas para la Educación, la Ciencia y la Cultura (unesco). (2013) El futuro del aprendizaje móvil. Implicaciones para la planificación y la formulación de políticas. Organización de las Naciones Unidas para la Educación, la Ciencia y la Cultura, http://unesdoc.unesco.org/images/0021/002196/219637s.pdf.

\section{Cómo CITAR ESTE ARTículo}

* Martínez Pérez, Jesús y Martínez Cuatepotzo, Berenice. (2021, marzo-abril). La fotografía en el aula de ciencias: propuestas didácticas. Revista Digital Universitaria (RDU), 22(2). Dol: http://doi.org/10.22201/cuaieed.16076079e.2021.22.2.8 